\title{
Acetate and plasma cholesterol as progesterone precursors in the intact ovary of the Day-16 pregnant rat*
}

\author{
R. T. Swann and N. W. Bruce \\ Department of Anatomy and Human Biology, The University of Western Australia, Nedlands, \\ Western Australia 6009, Australia
}

\begin{abstract}
Summary. Rats at Day 16 of pregnancy were infused, via the parametrial artery, with radioactively labelled acetate or cholesterol. All of the venous effluent was collected and examined for radioactive progesterone and related compounds. Labelled progesterone was found in the venous effluent within 15 and $30 \mathrm{~min}$ of the start of cholesterol and acetate infusions, respectively, which shows that the ovary can extract both precursors from blood and convert them to progesterone in the intact animal. However, the proportion of secreted progesterone derived from acetate (estimated from labelled progesterone in venous blood) was only $0.21 \pm 0 \cdot 10 \%$ (mean \pm s.e.m.; $n=5$ ). Furthermore, the quantity of labelled progesterone and immediate progesterone precursors remaining in the ovary indicated that less than $0.22 \pm 0 \cdot 10 \%$ of progesterone could have been derived from acetate. In contrast, in rats infused with labelled cholesterol $42 \pm 9 \%$ of the progesterone was derived from this source and, from labelled progesterone and immediate precursors of progesterone remaining in the ovary, it was calculated that $53 \pm 10 \%$ could have been derived from blood-borne cholesterol.
\end{abstract}

\section{Introduction}

Progesterone synthesis in the rat ovary involves cholesterol as an obligatory precursor of progesterone but the source of this cholesterol within the cell remains unclear (Enders, 1973; Strauss, Schuler, Rosenblum \& Tanaka, 1982). Many earlier workers have implied that a significant proportion of cholesterol is synthesized in the luteal cell from acetate (McNamara, Cranna, Booth \& Stansfield, 1980; Azhar \& Menon, 1981). The luteal cell is enzymically competent to convert acetate through cholesterol to progesterone (Savard, 1973) and, in many studies, acetate is used in vitro as a carbon source for progesterone synthesis (Major, Armstrong \& Greep, 1967). Furthermore, the concentration of acetate in plasma (Ballard, 1972) is adequate to support normal rates of progesterone secretion. However, the luteal cell obtains most of its cholesterol directly from blood associated with either high density (HDL) or low density (LDL) lipoproteins (McNamara, Booth \& Stansfield, 1981; Tureck, Wilburn, Gwynne, Paavola \& Strauss, 1983). It has been shown in vitro that high levels of cholesterol outside the cell inhibit the utilization of acetate in the cell (Schuler, Toaff \& Strauss, 1981) but whether a similar mechanism operates in vivo is not known.

The objective of the present work was to examine quantitatively the importance of blood-borne acetate and cholesterol as precursors of progesterone. Such information is essential for clearer interpretation of quantitative histological studies on the corpus luteum (CL) the structure of which is related to rates of steroid synthesis (Meyer \& Bruce, 1984). Much of the work, however, was directed at developing an experimental model so that a wide range of biochemical mechanisms within the ovary could be studied under near physiological conditions.

\footnotetext{
* Reprint requests to N. W. Bruce.
} 


\section{Materials and Methods}

Nulliparous albino Wistar rats, 3-5 months old, were used. The 20 rats were kept in an environmentally controlled room $\left(17-23^{\circ} \mathrm{C}\right.$, relative humidity $50-70 \%$, lights on from $07: 00$ to $21: 00 \mathrm{~h}$ ). Food and water were freely available. Rats were mated during darkness and the morning on which spermatozoa were found in a vaginal smear was called Day 1 of gestation. Rats from this colony normally litter on the morning of Day 23. The rats were prepared on Day 16 of gestation.

\section{Reagents and substrate preparation}

Labelled acetate ([U- $\left.{ }^{14} \mathrm{C}\right]$ acetate, sodium salt, sp. act. $59.6 \mathrm{mCi} / \mathrm{mmol}$; Amersham Australia, Sydney, Australia) was dissolved in $0.9 \%(\mathrm{w} / \mathrm{v}) \mathrm{NaCl}$ to give a radioactivity of $277 \times 10^{5} \mathrm{~d} . \mathrm{p} . \mathrm{m} . / \mathrm{ml}$ (in Exp. 1, 150-200 × 105 d.p.m. $/ \mathrm{ml}$ ).

Labelled cholesterol $\left(\left[4-{ }^{14} \mathrm{C}\right]\right.$ cholesterol, in toluene; sp. act. $58.4 \mathrm{mCi} / \mathrm{mmol}$; Amersham Australia) was incorporated into rat plasma by following the method of Avigan (1959). The labelled plasma $\left(20-50 \times 10^{5}\right.$ d.p.m./ml; in Exp. 1, 5-8 $\left.\times 10^{5} \mathrm{~d} . \mathrm{p} . \mathrm{m} . / \mathrm{ml}\right)$ was used for infusion into the rat within $8 \mathrm{~h}$ of preparation.

All solvents used were analytical reagent grade and were obtained from David Brown Scientific, Perth, Australia, or from Mallinckrodt Incorporated, Paris, KY, U.S.A. Progesterone, 20 $\alpha$ dihydroprogesterone and cholesterol were obtained from Sigma Chemical Company, St Louis, MO, U.S.A. and the progesterone (P11-192) and 20 $\alpha$-dihydroprogesterone (P20-3) antibodies from Endocrine Sciences, Tarzana, CA, U.S.A. Heparin was supplied by Commonwealth Serum Laboratories, Melbourne, Australia. Plates for thin-layer chromatography were obtained from E. Merck, Darmstadt, West Germany. The aqueous scintillant was mixed in our laboratory from toluene and Triton X-100 (2:1, v/v; Ajax Chemicals, Sydney, Australia) with 2,5-diphenyloxazole (PPO, 0.45\%, w/v; Sigma).

\section{Surgery and the venous outflow circuit}

The venous outflow technique was modified from that described previously (Bruce, Meyer \& Dimmitt, 1980). Essentially it consisted of a cannula inserted into the parametrial artery so that substrates could be infused directly with minimal interference to the major arterial supply, the ovarian artery. The venous drainage was isolated and the parametrial vein cannulated so as to collect the entire venous effluent and prevent recirculation.

An additional cannula (polyethylene tubing with a tip fashioned from a 30-gauge stainless-steel needle with a rounded end) was inserted into the parametrial artery just before its anastomosis with the ovarian artery (see Dharmarajan, Meyer \& Bruce, 1983). A ligature was positioned around the ovarian vein but not tied until the venous drainage into the parametrial cannula was established. All other vessels which anastomosed between the ovary and the upper portion of the uterus were ligated as were vessels anastomosing with the renal vessels. When the operation was complete, the abdomen of the rat and all exposed viscera were immersed in a bath of $0.9 \%(\mathrm{w} / \mathrm{v}) \mathrm{NaCl}$ at $37^{\circ} \mathrm{C}$ to maintain body heat and prevent tissue dehydration. The rat was allowed to stabilize in the bath for about $15 \mathrm{~min}$ and heart rate, blood pressure and ovarian blood flow were continuously monitored. Three arterial and venous blood samples were taken at 20 -min intervals to determine a baseline secretion rate for progesterone. During this stage the remaining venous effluent was returned to the rat via the jugular cannula, together with an appropriate volume of donor blood to replace that lost due to sampling. The donor blood was taken from rats in dioestrus to avoid peak levels of gonadotrophins.

\section{Infusion of substrates and sample collection}

Labelled acetate or cholesterol was infused into the parametrial artery of the rat for a period of 
$2 \mathrm{~h}(2-4 \mathrm{~h}$ in Exp. 1), at a rate of $0.02 \mathrm{ml} / \mathrm{min}$ (Syringe pump model 351, Sage Instruments, MA, U.S.A.). The infusion rate, expressed as radioactivity (c.p.m.) per minute, was checked before and after the infusion.

During the infusion, the ovarian venous blood was collected in its entirety (as 15-min samples) and the volume of blood collected was replaced with donor blood via the jugular cannula. Each sample was haemolysed with twice its volume of double-distilled water and stored at $-10^{\circ} \mathrm{C}$ until analysed. At the end of the infusion period the ovary and surrounding structures, including oviduct and periovarian fat, were removed and immediately frozen in liquid nitrogen, to minimize further metabolism, and stored at $-10^{\circ} \mathrm{C}$ until analysed. To determine whether the ovarian venous drainage had been completely isolated, a sample of liver $(0.5-1.0 \mathrm{~g})$ was removed, frozen and subsequently examined for traces of radioactivity.

\section{Analysis}

Portions of each blood sample $(0.5 \mathrm{ml})$ were extracted with chloroform/methanol $(1: 2, \mathrm{v} / \mathrm{v})$ by the method of Bligh \& Dyer (1959). The steroids in the chloroform phase were separated and identified by thin-layer chromatography and the general method as described by Waddell \& Bruce (1984) was followed, although, in addition to progesterone, $20 \alpha$-dihydroprogesterone, cholesterol and pregnenolone were identified. The radioactivity of these compounds was determined as outlined for progesterone (Waddell \& Bruce, 1984), taking into account procedural losses.

The water-soluble compounds in the methanol-water phase were treated as a single group. The total label in this fraction was then determined by liquid scintillation counting (Isocap 300, Searle Analytic, Des Plaines, IL, U.S.A.) with an external standard for quench correction.

Ovarian tissues were dissected while still frozen. The CL of pregnancy were separated from those of previous cycles on the basis of gross morphology and weight (Bruce, Meyer \& Dharmarajan, 1984). Ovarian stroma, the upper portion of the oviduct and a portion of the peri-ovarian adipose tissue were also separated and weighed. Each frozen tissue sample was homogenized in chloroform: methanol:water (1:2:0.8 by vol; Ultra-turrax, Janke and Kunkel, Germany). The phase was broken by addition of chloroform $(1 \mathrm{ml})$ and water $(1 \mathrm{ml})$ and the samples centrifuged at $700 \mathrm{~g}$ for $10 \mathrm{~min}$; the two phases were then analysed as outlined for blood samples.

The concentration of total cholesterol and HDL cholesterol in rat plasma were determined by the cholesterol oxidase method (Sigma). This method was used to determine the concentrations in the infused plasma and to determine the endogenous concentrations in the plasma of infused rats. The coefficient of variation for total cholesterol was $1.65 \%(n=10$, repeated plasma sample) and HDL cholesterol was $1.87 \%$. Recovery of exogenous cholesterol added to rat plasma was $98 \cdot 9 \pm 0 \cdot 71 \%(n=5)$.

RIA was used to determine endogenous progesterone (Meyer \& Bruce, 1979) and 20 $\alpha$-dihydroprogesterone (Dharmarajan, Bruce \& McArdle, 1986) concentrations. The detection limit for progesterone was $10 \mathrm{pg}$ per assay tube and the intra- and inter-assay coefficients of variation were $6.5 \%$ and $7 \cdot 2 \%$ respectively. The detection limit for $20 \alpha$-dihydroprogesterone was $10 \mathrm{pg}$ per assay tube and the intra- and inter-assay coefficients of variation were $6.5 \%$ and $8.4 \%$ respectively.

\section{Expressions used in the results}

Three estimates of the percentage of progesterone secreted by the ovary and synthesized from substrate are presented in the results.

(1) Pven \% is the percentage of venous progesterone derived from labelled substrate as calculated from the activity of labelled progesterone in the venous effluent. This value does not consider the potential contribution of the pool of labelled substrates and products remaining in the ovary at the end of the infusion period. 
(2) $\mathrm{P} t i s \%$ is an estimate of the latter contribution and is defined as the maximum possible percentage of progesterone that would be secreted into ovarian venous blood if all the labelled substrate and products remaining in the ovary were destined to be converted to progesterone.

(3) $\mathrm{Pmax} \%$ is the maximum percentage of progesterone secreted into ovarian blood that could be derived from the substrate, as determined by addition of Pven $\%$ at the end of the infusion and Ptis\%.

Similar expressions (20Aven $\%, 20 \mathrm{~A}$ tis $\%$ and $20 \mathrm{Amax} \%$ ) were used to calculate the percentage of $20 \alpha$-dihydroprogesterone synthesized from the substrate.

\section{Calculation of results}

$$
\mathrm{Pven} \%=\left(\mathrm{P}^{*} \times \mathrm{f} \times \mathrm{S} \times 100\right) /\left(\mathrm{S}^{*} \times \operatorname{Pr} \times \mathrm{N}\right)
$$

where $\mathrm{f}=$ ovarian blood flow $(\mathrm{ml} / \mathrm{min}) ; \mathrm{S}=$ concentration of endogenous substrate in arterial blood $(\mu \mathrm{M}) ; \mathrm{P}^{*}=$ labelled progesterone in 1 -min sample of ovarian venous blood (c.p.m./min); $\mathrm{S}^{*}=$ labelled substrate infused per $\min$ (c.p.m./min); $\mathrm{Pr}=$ secretion rate of progesterone into ovarian venous blood ( $\mathrm{nmol} / \mathrm{min}$ ); $\mathrm{N}=$ number of moles of substrate incorporated into 1 mole of progesterone, 11 for acetate (as calculated from data presented by Bloch, 1965), and 1 for cholesterol. The endogenous concentration of acetate (S) was taken as $116 \mu \mathrm{M}$ as reported by Ballard (1972) while cholesterol concentration was determined as described above. The secretion rate of progesterone (Pr) was determined immediately before and at the end of the infusion period.

$$
\mathrm{P} t i s \%=\left(\mathrm{S}(\mathrm{tis})^{*} \times \mathrm{f} \times \mathrm{S} \times 100\right) /\left(\mathrm{S}^{*} \times \mathrm{Pr} \times \mathrm{N} \times \mathrm{t}\right)
$$

where $t$ is the total period of infusion $(\mathrm{min}) ; \mathrm{S}(\mathrm{tis})^{*}$ is labelled progesterone or potential precursors found in the ovary (c.p.m.) and $\mathrm{Pr}$ is the mean of the progesterone secretion values determined before and after the infusion period.

(3)

$$
\mathrm{P} \max \%=\mathrm{P} v e n \%+\mathrm{P} t i s \%
$$

where $\mathrm{P} v e n \%$ was estimated near the end of the infusion period. A typical worked example is given below.

Rat 1 was infused with labelled cholesterol for a period of $120 \mathrm{~min}$ and its values were: $\mathrm{f}=0.31 \mathrm{ml} / \mathrm{min}, \mathrm{S}=1510 \mu \mathrm{M}, \mathrm{P}^{*}=16.1 \mathrm{c.p} . \mathrm{m} . / \mathrm{min}, \mathrm{S}^{*}=21303 \mathrm{c.p} . \mathrm{m} . / \mathrm{min}, \mathrm{Pr}=0.869 \mathrm{nmol} /$ $\min , \mathrm{N}=1, \mathrm{~S}(\mathrm{tis})^{*}=522$ c.p.m.; therefore,

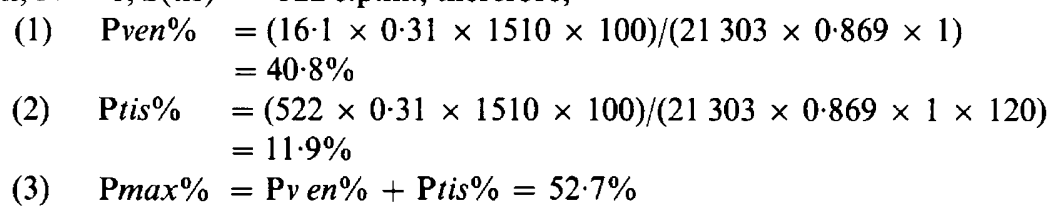

\section{Results}

\section{General}

Two experiments were carried out and, in each, 5 rats were infused with labelled acetate and 5 with labelled cholesterol. In the second experiment, a higher specific activity of substrate was used thus reducing the variance in results. In addition, assays of $20 \alpha$-dihydroprogesterone and HDL cholesterol were carried out. The major results from both experiments were similar: those from the second are presented in detail, together with the relevant findings from those of the first.

There were no significant differences (unpaired $t$ test) between acetate- and cholesterol-infused rats in weight gain during pregnancy (respectively, $50 \pm 5$ and $55 \pm 2$ g; mean \pm s.e.m.; $N=5$ ), luteal tissue weight $(29.9 \pm 1.5$ and $35.1 \pm 6.6 \mathrm{mg})$, number of large $\mathrm{CL}(7.8 \pm 0.6$ and $8.2 \pm 1.1)$ or the mean CL weight of the infused ovary (3.9 \pm 0.1 and $4.3 \pm 0.2 \mathrm{mg})$. Arterial blood pressure, 
heart rate, ovarian blood flow and arterial progesterone and 20 0 -dihydroprogesterone concentrations were stable over the duration of the infusion and did not differ between the two groups. Progestagen secretion rates, although stable throughout the infusion, were appreciably higher in the acetate-infused group. There was, however, considerable variation between rats and group means were not significantly different and fell within the range of values previously observed (Bruce \& Meyer, 1981).

The contents of progesterone and $20 \alpha$-dihydroprogesterone in the large CL at the end of the infusion were similar in acetate-infused rats $(1.495 \pm 0.272$ and $0.1006 \pm 0.0154 \mathrm{nmol} /$ ovary, respectively) and cholesterol-infused rats (1.612 \pm 0.216 and $0.1094 \pm 0.0148 \mathrm{nmol} /$ ovary). Furthermore, the concentration of steroids was comparable in the large and small CL of the infused ovary of both groups (Table 1).

Table 1. Physiological data, progestagen concentrations and secretion rates in rats infused with radioactively labelled acetate or cholesterol

\begin{tabular}{|c|c|c|c|c|}
\hline \multirow[b]{2}{*}{ Time of infusion } & \multicolumn{2}{|c|}{ Acetate-infused rats } & \multicolumn{2}{|c|}{ Cholesterol-infused rats } \\
\hline & Start & End & Start & End \\
\hline Arterial pressure $(\mathrm{mmHg})$ & $129 \pm 11$ & $145 \pm 8$ & $121 \pm 6$ & $123 \pm 8$ \\
\hline Heart rate (beats/min) & $354 \pm 11$ & $400 \pm 29$ & $368 \pm 12$ & $350 \pm 7$ \\
\hline \multicolumn{5}{|l|}{ Arterial conc. (nM) } \\
\hline Progesterone & $205 \pm 9$ & $204 \pm 38$ & $179 \pm 22$ & $175 \pm 14$ \\
\hline $20 \alpha$-Dihydroprogesterone & $94 \pm 8$ & $78 \pm 16$ & $84 \pm 10$ & $90 \pm 32$ \\
\hline Blood flow ( $\mathrm{ml} / \mathrm{min}$ per ovary) & $0.46 \pm 0.09$ & $0.37 \pm 0.07$ & $0 \cdot 33 \pm 0 \cdot 10$ & $0.33 \pm 0.08$ \\
\hline \multicolumn{5}{|l|}{ Ovarian secretion ( $\mathrm{nmol} / \mathrm{min})$} \\
\hline Progesterone & $1.85 \pm 0.38$ & $1.51 \pm 0.33$ & $1 \cdot 15 \pm 0.47$ & $0.96 \pm 0.25$ \\
\hline 20a-Dihydroprogesterone & $0.59 \pm 0.10$ & $0.56 \pm 0 \cdot 10$ & $0.29 \pm 0.07$ & $0.38 \pm 0.08$ \\
\hline Total progestagens & $2.44 \pm 0.45$ & $2.07 \pm 0.36$ & $1.44 \pm 0.47$ & $1.34 \pm 0.32$ \\
\hline \multicolumn{5}{|l|}{ Tissue conc. $(\mathrm{nmol} / \mathrm{g})$} \\
\hline \multicolumn{5}{|l|}{ Progesterone } \\
\hline Large CL & & $50.0 \pm 9 \cdot 0$ & & $44 \cdot 0 \pm 2 \cdot 0^{*}$ \\
\hline Small CL & & $38.5 \pm 0.5$ & & $25 \cdot 8 \pm 5 \cdot 4$ \\
\hline \multicolumn{5}{|l|}{$20 \alpha$-Dihydroprogesterone } \\
\hline Large $C L$ & & $3.38 \pm 0.5$ & & $2 \cdot 99 \pm 0.1^{*}$ \\
\hline Small CL & & $3.20 \pm 0.6$ & & $1.54 \pm 0.3$ \\
\hline \multicolumn{5}{|l|}{ Cholesterol $\left(\times 10^{-3}\right)$} \\
\hline Large CL & & $77 \cdot 7 \pm 2 \cdot 3$ & & $71 \pm 3 \cdot 1$ \\
\hline
\end{tabular}

Values given are means \pm s.e.m. $(\mathrm{N}=5$ ). There was no significant difference between group means (unpaired $t$ tests) or between values at the start and end of infusion within groups (paired $t$ tests).

* Significantly different from the corresponding small CL value $(P<0.01$, paired $\imath$ tests $)$.

\section{Acetate infusion}

No labelled progesterone was detected in the venous effluent during the first 15 min of infusion (Table 2). By the second sample (15-30 min after the start of infusion) labelled progesterone was detected in the venous blood, but the calculated Pven\% was negligible and did not change significantly over the infusion period. The small quantity of stored labelled progesterone and progesterone precursors within the ovary meant limited tissue contribution to the total amount of progesterone synthesized from acetate. The theoretical maximum contribution for progesterone derived from acetate, including the possible tissue contribution, never exceeded $1 \%$.

Labelled $20 \alpha$-dihydroprogesterone also was detected in the second sample (15-30 $\mathrm{min})$ but not in the first. The percentage of $20 \alpha$-dihydroprogesterone derived from the infused acetate showed no significant difference from that for progesterone. 
Table 2. Utilization of acetate and cholesterol as precursors of progestagens in the rat ovary

\begin{tabular}{|c|c|c|}
\hline & Acetate & Cholesterol \\
\hline Pven $\%(0.25 \mathrm{~h})$ & None detected & $29 \cdot 9 \pm 12 \cdot 1$ \\
\hline Pven $\%(0-5 \mathrm{~h})$ & $0.09 \pm 0.02$ & $41 \cdot 2 \pm 10 \cdot 6$ \\
\hline Pven $\%$ (end) & $0.21 \pm 0.10$ & $42.4 \pm 8 \cdot 9^{*}$ \\
\hline Ptis\% & $0.004 \pm 0.003$ & $10.5 \pm 4.3$ \\
\hline $\mathrm{P} \max \%$ & $0 \cdot 214 \pm 0 \cdot 10$ & $52.9 \pm 10 \cdot 0^{*}$ \\
\hline 20 Aven $\%(0.25 \mathrm{~h})$ & None detected & $26.9 \pm 8.2$ \\
\hline $20 \mathrm{Aven} \%(0.5 \mathrm{~h})$ & $0.02 \pm 0.006$ & $64 \cdot 7 \pm 14 \cdot 1$ \\
\hline 20 Aven $\%$ (end) & $0.14 \pm 0.06$ & $78 \cdot 3 \pm 13 \cdot 3$ \\
\hline $20 \mathrm{~A}$ tis $\%$ & $0.001 \pm 0.00 \mathrm{I}$ & $10.9 \pm 3.9$ \\
\hline $20 \mathrm{~A} \max \%$ & $0.141 \pm 0.06$ & $89.1 \pm 12 \cdot 3$ \\
\hline
\end{tabular}

The values given are mean \pm s.e.m. $(\mathrm{N}=5)$.

* Significantly different from the corresponding $20 \alpha$-dihydroprogesterone value $(P<0.05$, unpaired $t$ test $)$.

The comparable results from the first experiment, in which only limited measurements were taken, were similar; Pven \% after $30 \mathrm{~min}$ was $0.19 \pm 0.04 \%$ and at the end of the infusion was $1.48 \pm 0.81 \%$; Ptis $\%$ was $0.51 \pm 0.23 \%$ and $\mathrm{P}$ max $\% 1.98 \pm 1.02 \%$. These figures were not significantly different from those of the second experiment (unpaired $t$ test) even though ovarian blood flow $(0 \cdot 180 \pm 0.028 \mathrm{ml} / \mathrm{min})$ and progesterone secretion rate $(1.336 \pm 0.222 \mathrm{nmol} / \mathrm{min})$ were substantially lower.

No radioactivity was detected in the liver samples of either experiment, indicating that there was no significant recirculation of labelled compounds.

\section{Cholesterol infusion}

A substantial quantity of labelled progesterone was detected in the first sample $(0-15 \mathrm{~min}$ infusion) and resulted in a Pven $\%$ of $30 \%$ (Table 2). There was an apparent, but not significant, increase to $41 \%$ by the second sample (15-30 min) and no change thereafter. The Ptis\% was only one quarter of that of Pven \% and so the store of labelled progesterone and precursors within the ovary made only limited contribution to $\mathrm{Pmax} \%$.

Labelled $20 \alpha$-dihydroprogesterone also was detected in the first sample. Calculation of the percentage of $20 \alpha$-dihydroprogesterone derived from labelled cholesterol yielded somewhat higher figures than those for progesterone, significant only for $20 \mathrm{Aven} \%$ at the end of the infusion and $20 \mathrm{~A} \max \%$.

The total cholesterol concentration (cholesterol and cholesterol esters) in plasma in the 5 rats was $1485 \pm 16.8 \mu \mathrm{M}$ and of this $1022 \pm 60 \mu \mathrm{M}$ or $69 \%$ was found in the HDL fraction. Similar values were found in the infused plasma; the total cholesterol was $1532 \pm 24 \mu \mathrm{M}$ and that in the HDL fraction was $1088 \pm 90 \mu \mathrm{M}$ or $71 \%$ of the total. The label appeared to distribute evenly in the plasma since $78 \pm 5 \%$ was associated with the HDL fraction.

Labelled progesterone and $20 \alpha$-dihydroprogesterone were found in large and small $\mathrm{CL}$. The concentrations (c.p.m./g tissue) of each were higher in the small CL $(22.4 \pm 4.3$ and $43.9 \pm 23$, respectively) than in the large $C L(8 \cdot 8 \pm 2 \cdot 1$ and $17 \cdot 8 \pm 10 \cdot 2)$, although the difference was only significant for the progesterone values. The concentration of labelled cholesterol measured only in the large $\mathrm{CL}$ was $54 \times 104$ c.p.m./g tissue and no labelled pregnenolone was detected. The specific activity of cholesterol ( 7 c.p.m./g CL) was approximately $25 \%$ of that found in the blood.

The results from the first experiment, in which a lower specific activity of label was used, were highly variable. The Pven \% at 30 min was $12.5 \pm 6.8$ and at the end of infusion was $14.7 \pm 5.4 \%$. The tissue contribution Ptis\% was $60 \cdot 2 \pm 36 \cdot 3 \%$ and $\mathrm{P} \max \%$ was $73 \cdot 7 \pm 34 \cdot 3 \%$. 
No radioactivity was detected in the liver samples in either experiment, indicating that there was no significant recirculation of labelled compounds.

\section{Discussion}

The aim of this work was to develop a preparation for examining biochemical aspects of steroidogenesis under conditions that were as physiological as practicable and specifically to examine blood-borne acetate and cholesterol as precursors of ovarian steroids.

Overall, the preparation was successful, and we expect it will be applied to a range of other biochemical investigations such as oxygen consumption previously examined only under in-vitro conditions in the rat (Barker \& Schwartz, 1953). The main disadvantage is the necessity for anaesthesia, although blood pressure and pulse rate are close to those expected in conscious, normal rats (Waddell \& Bruce, 1984). The main advantage of the preparation is that the ovary is perfused with the rat's own blood, delivered under normal physiological temperature, pressure and pulsatile conditions. Furthermore, after the initial surgery and positioning of cannulae, no further manipulation is required. The ovary remains in situ, enclosed within the ovarian bursa and related to its normal adjacent tissues including oviduct and periovarian fat. The volume of tracer solution infused can be kept to less than $15 \%$ of the total blood supply to the ovary and the mass of labelled substrate itself to less than $10 \%$ of endogenous supply.

The present study provides the first quantitative evidence that both acetate and cholesterol, circulating in the blood, are taken up by the $\mathrm{CL}$, converted into progesterone and secreted into the venous effluent. In an earlier qualitative study, Nishizawa \& Eik-Nes (1964) reported that, in some dogs treated with large doses of human chorionic gonadotrophin, acetate was converted to progesterone in the ovary. From the present analysis, however, it is clear that acetate has only a minor role: at most it accounted for less than $0.5 \%$ of the total progestagens secreted whereas cholesterol accounted for over $50 \%$. In in-vitro studies in which cholesterol was added to the incubation media, progesterone secretion was increased (Azhar \& Menon, 1981) and the conversion of acetate to cholesterol was decreased (Schuler et al., 1981). These findings together with those of in-vivo studies in which cholesterol-depleted rats were shown to have lower plasma progesterone concentrations (Schuler et al., 1981) have led to the view that cholesterol in arterial blood is the more important precursor. Results from the present study provide quantitative support for this view. The question remains, however, as to why acetate is used at all by the ovary. It may act as a reserve mechanism with a more active role if the concentration of cholesterol in blood is reduced or the transport of cholesterol into the luteal cell is impaired. Alternatively, the enzymic capacity of the ovary to convert acetate to cholesterol might simply relate to the development and biochemical differentiation of all steroidogenic tissues. Certainly both the testis (van der Molen \& Rommerts, 1981) and adrenal cortex (Simpson \& Mason, 1976) can convert acetate to cholesterol, but quantitative studies similar to those of the present work, have not been undertaken. General patterns of precursor utilization by steroidogenic tissues therefore remain to be formulated.

Cholesterol from blood was the major precursor used but in the present study could have accounted for only half of the progesterone synthesized. That it did not account for $100 \%$ of the secreted progesterone raises the following possibilities. Firstly, its actual use was underestimated. This could have happened if, during incubation, the labelled cholesterol partitioned into fractions unavailable for steroidogenesis. It was assumed that labelled cholesterol entered the various lipoprotein fractions in the same proportions as their endogenous cholesterol content. This seemed true, at least for the major division of $\mathrm{HDL}$ and LDL fractions. But there is controversy as to whether HDL or LDL is the major carrier of cholesterol into the rat ovary (Azhar \& Menon, 1981; Paavola \& Strauss, 1983) and it is possible that luteal cells discriminate between the various subfractions of lipoproteins. Further investigation in this area would require accurate specification of likely biologically relevant sub-fractions and methods of labelling them to high activity without 
affecting their physiological characteristics. Secondly, it is possible that some of the progesterone secreted was derived by decreasing the cholesterol stores within the luteal cells. This seems unlikely since the cholesterol stores at the end of the experiment $(27.7 \pm 1.2 \mathrm{mg} / \mathrm{g} \mathrm{CL}$ tissue) were even greater than those observed in rats at an equivalent stage of pregnancy which had not been subject to venous outflow measurements $(10.7 \pm 0.52 \mathrm{mg} / \mathrm{g} \mathrm{CL}$; Uchida, Kadowaki, Nomura, Miyata \& Miyake, 1970). Certainly the progesterone secreted could not have come from progesterone stores since those would have accounted only for $1.4 \mathrm{~min}$ of secretion, similar to the value of $1.8 \mathrm{~min}$ calculated by Uchida et al. (1970). Finally, it is possible that other precursors have a significant role in steroidogenesis. This might be difficult to examine, particularly if there are a number of precursors each making a small contribution to progesterone synthesis.

The finding that blood-borne cholesterol is the major precursor used for progesterone synthesis is particularly relevant to morphometric studies on steroidogenic tissue. Attempts have been made to relate structure such as quantity or surface area of steroidogenic organelles, to rates of steroid secretion (Mori \& Christensen, 1980; Zirkin, Ewing, Kromann \& Cochran, 1980). Meyer \& Bruce (1984), however, pointed out that steroid secretion per unit membrane appears 50 times higher in the luteal cell than in the Leydig cell of the rat. An explanation given was that, if the Leydig cell used acetate and the luteal cell used cholesterol as precursors, then a greater quantity of steroidogenic organelles might be required by the Leydig cell for the additional process of converting acetate to cholesterol. The present results support this explanation though clearly more work needs to be done on establishing biochemical pathways used by steroidogenic tissue under physiological conditions.

Some insight into the intracellular dynamics of progesterone synthesis arises from the finding that, even in the first $15 \mathrm{~min}$ of infusion, blood-borne cholesterol accounted for $30 \%$ of the progesterone secreted. Since this was close to the apparently steady state value for Pven $\%$ over the remaining $2 \mathrm{~h}$ of infusion it indicates that transport of cholesterol into the luteal cell, conversion to progesterone and secretion back into the blood can be extremely rapid. Although it has been suggested that uptake of cholesterol is a rate-limiting step to steroidogenesis (Strauss et al., 1982), this did not appear to be so in the present study. Specific studies of cholesterol transport, similar to those used for steroid hormones (Pardridge, 1981) would be needed to confirm this point. In addition, the luteal cell contains a large store of cholesterol esters $(11.5 \%$ by weight, Flint $\&$ Armstrong, 1972) and cholesterol entering the cell could be directed into this store or direct to mitochondria and hence to progesterone. From the values of $\mathrm{P} t i s \%$ and $\mathrm{P} v e n \%$ it seems that only a small proportion entered the store whereas most was taken directly to progesterone. Flint \& Armstrong (1972) computed likely fractional turnover rates for this store $\left(0 \cdot 27 \mathrm{~h}^{-1}\right)$ and this value is compatible with the results of the present work in which the specific activity of cholesterol within the luteal tissue was $25 \%$ of that of the arterial blood by $2 \mathrm{~h}$.

Analysis of ovarian tissues at the end of the infusion period showed that the large CL, small CI and ovarian stroma retained both acetate and cholesterol precursors. Sequestration does not necessarily indicate uptake for progesterone synthesis, much of it might be used for general metabolism of the cell and, particularly with cholesterol, for synthesis and turnover of lipoprotein membranes. The appearance of labelled progesterone, however, indicates de-novo synthesis of hormone by that tissue. As expected, the large $\mathrm{CL}$ of pregnancy contained substantial quantities of labelled progesterone, confirming their role as a major source of progesterone in the pregnant rat (Uchida et $a l ., 1970)$. The finding of labelled progesterone in the small CL is the first direct indication that this tissue also synthesized progesterone during pregnancy. Furthermore the specific activity of the progesterone suggests that this synthesis proceeds at a rate at least equivalent to that of the large CL (per mg). Little is known about these small CL but we found that their rate of growth over the first half of gestation, their high rate of blood flow and histological appearance, were similar to those of the large CL of pregnancy (Bruce et al., 1984). They are derived from CL of previous cycles and although they reach only about $25 \%$ of the volume of the CL of pregnancy, it is now clear that they are not only rescued by subsequent pregnancy but retain some capacity for steroidogenesis. 
In conclusion, this work shows that acetate is of little physiological importance as a bloodborne precursor of progesterone. Furthermore, evidence is presented of a major role for plasma cholesterol as a precursor of both progesterone and $20 \alpha$-dihydroprogesterone. In addition a useful preparation has been developed that can be applied to various aspects of ovarian metabolism under near physiological conditions. Quantitative estimates can be made of the significance of alternative synthetic pathways and information obtained on the timing of transport processes and the synthetic steps involved.

We thank Professor J. Maserai for advice on cholesterol assay and Mr A. Stuart for technical assistance. Financial support was received from the Australian Research Grants Scheme. R.T.S. was supported by a University of Western Australia Research Studentship.

\section{References}

Avigan, J. (1959) A method for incorporating cholesterol and other lipides into serum lipoproteins in vitro. $J$. biol. Chem. 234, 787-790.

Azhar, S. \& Menon, K.M.J. (1981) Receptor-mediated gonadotropin action in the ovary. J. biol. Chem. 256, 6548-6555.

Ballard, F.J. (1972) Supply and utilization of acetate in mammals. Am. J. clin. Nutr. 25, 773-779.

Barker, S.B. \& Schwartz, H.S. (1953) Further studies on metabolism of tissues from thyroxine-injected rats. Proc. Soc. exp. Biol. Med. 83, 500-502.

Bligh, E.G. \& Dyer, W.J. (1959) A rapid method of total lipid extraction and purification. Can. J. Biochem. Physiol. 37, 911-917.

Bloch, K. (1965) The biological synthesis of cholesterol. Science, N.Y. 150, 19-28.

Bruce, N.W. \& Meyer, G.T. (1981) Ovarian blood flow and progesterone secretion in anaesthetized rats at Day 16 of gestation, and the effects of haemorrhage. J. Reprod. Fert. 61, 419-423.

Bruce, N.W., Meyer, G.T. \& Dimmitt, S.B. (1980) Progesterone secretion and ovarian blood flow in the pregnant rat. $J$. Endocr. 85, 327-330.

Bruce, N.W., Meyer, G.T. \& Dharmarajan, A.M. (1984) Rate of blood flow and growth of the corpora lutea of pregnancy and of previous cycles throughout pregnancy in the rat. J. Reprod. Fert. 71, 445-452.

Dharmarajan, A.M., Meyer, G.T. \& Bruce, N.W. (1983) Morphometric analysis of the corpus luteum of 16-Day pregnant rats: the effect of preparative procedures on volume of luteal cell, interstitial, and vascular compartments. Am. J. Anat. 168, 51-65.

Dharmarajan, A.M., Bruce, N.W. \& McArdle, H.J. (1986) Comparison of flow rates and composition of ovarian lymph and blood in the Day-16 pregnant rat. J. Reprod. Fert. 77, 169-176.

Enders, A.C. (1973) Cytology of the corpus luteum. Biol. Reprod. 8, 158-182.

Flint, A.P.F. \& Armstrong, D.T. (1972) Dynamic aspects of ovarian cholesterol metabolism: regulation by gonadotropins. In Gonadotrophins, pp. 269-286. Eds B. B. Saxena, C. G. Beling \& H. M. Gandy. Wiley Interscience, New York.

Major, P.W., Armstrong, D.T. \& Greep, R.O. (1967) Effect of $\mathrm{LH}$ in vivo and in vitro on cholesterol con- version to progestins in rat corpus luteum tissue. Endocrinology 81, 19-28.

McNamara, B.C., Cranna, C.E.G., Booth, R. \& Stansfield, D.A. (1980) The preparation and purification of isolated rat corpus luteum cells and their use in studying the relationship between cholesterol biosynthesis and lutropin-stimulated formation of progesterone. Biochem. J. 192, 559-567.

McNamara, B.C., Booth, R. \& Stansfield, D.A. (1981) Evidence for an essential role for high-density lipoprotein in progesterone synthesis by rat corpus luteum. FEBS Lett. 134, 79-82.

Meyer, G.T. \& Bruce, N.W. (1979) Corpus luteum growth and plasma progesterone levels in unilaterally ovariectomized pregnant rats. Anat. Rec. 195, $311-316$

Meyer, G.T. \& Bruce, N.W. (1984) Quantitative ultrastructure of the luteal cell of the 16-day-pregnant rat and its relation to progesterone secretion. J. Reprod. Fert. 70, 261-269.

Mori, H. \& Christensen, A.K. (1980) Morphometric analysis of Leydig cells in the normal rat testis. J. Cell Biol. 84, 340-354.

Nishizawa, E.E. \& Eik-Nes, K.B. (1964) On the secretion of progesterone and $\Delta^{4}$-androstene-3,17-dione by the canine ovary in animals stimulated with human chorionic gonadotropin. Biochim. Biophys. Acta 86, 610-621.

Paavola, L.G. \& Strauss, J.F., III, (1983) Uptake of lipoproteins by in situ rat ovaries: identification of binding sites for high density lipoproteins. J. Cell Biol. 97 , 593-606.

Pardridge, W.M. (1981) Transport of protein-bound hormones into tissues in vivo. Endocr. Rev. 2, 103-123.

Savard, K. (1973) The biochemistry of the corpus luteum. Biol. Reprod. 8, 183-202.

Schuler, L.A., Toaff, M.E. \& Strauss, J.F., III (1981) Regulation of ovarian cholesterol metabolism: control of 3-hydroxy-3-methylglutaryl coenzyme A reductase and acyl coenzyme $A$ : cholesterol acyltransferase. Endocrinology 108, 1476-1486.

Simpson, E.R. \& Mason, J.I. (1976) Molecular aspects of the biosynthesis of adrenal steroids. Pharmacol. Ther. B. 2, 339-369. 
Strauss, J.F., III, Schuler, L.A., Rosenblum, M.F. \& Tanaka, T. (1982) Cholesterol metabolism by ovarian tissue. Adv. Lipid Res. 18, 99-157.

Tureck, R.W., Wilburn, A.B., Gwynne, J.T., Paavola, L.G. \& Strauss J.F., III, (1983) The role of lipoproteins in steroidogenesis by human luteinized granulosa cells in culture. J. Steroid Biochem. 19, 1033-1038.

Uchida, K., Kadowaki, M., Nomura, Y., Miyata, K. \& Miyake, T. (1970) Relationship between ovarian progestin secretion and corpora lutea function in pregnant rats. Endocr. japon. 17, 499-507.

van der Molen, H.J. \& Rommerts, F.F.G. (1981) Testicular steroidogenesis. In The Testis, pp. 213-238. Eds H. Burger \& D. de Kretser. Raven Press, New York.
Waddell, B.J. \& Bruce, N.W. (1984) Production rate, metabolic clearance rate and blood concentration of progesterone in conscious and anaesthetized pregnant rats. J. Endocr. 102, 357-363.

Zirkin, B.R., Ewing, L.L., Kromann, N. \& Cochran, R.C. (1980) Testosterone secretion by rat, rabbit, guinea pig, dog and hamster testes perfused in vitro: correlation with Leydig cell ultrastructure. Endocrinology 107, 1867-1874.

Received 18 December 1985 